\title{
O CFESS SE MANIFESTA EM PLENA PANDEMIA: Do luto à luta por direitos e liberdade!
}

\author{
Organizar a esperança, \\ Conduzir a tempestade \\ Romper os muros da noite, \\ Criar sem pedir licença \\ Um muro de liberdade. \\ Trabalhar a dor, trabalhar o dia, \\ Trabalhar a flor, irmão! \\ Tecendo nossas bandeiras \\ Na trama de cada dor. \\ Retomamos a memória, \\ Na batalha das cidades \\ Empunhamos nossa história \\ (...). \\ Pedro Tierra em Metal e sonho
}

Na trilha do poeta, seguimos transformando luto em luta, atravessando um longo e tortuoso túnel da história, vivenciando uma brutal crise societária, em seus elementos estruturais e conjunturais. A gestão do Conselho Federal de Serviço Social (Cfess), eleita para o triênio 2020-2023 Melhor ir à Luta com raça e classe e raça em defesa do Serviço Social assume a direção da entidade em um difícil contexto de crise estrutural do capital e crise conjuntural sanitária, política, econômica e institucional, na qual estamos mergulhados e mergulhadas. Nesse contexto, a categoria profissional vem sofrendo intensos processos de precarização do ensino, do trabalho, o que também é parte desta sociedade abatida pelo conservadorismo, mas segue com criatividade e resistência, articulada em espaços coletivos, como movimentos sociais, fóruns, sindicatos, partidos, na direção ou nas comissões dos conselhos regionais.

Nesta síntese-manifesto, socializamos algumas das ações e posicionamentos da entidade Cfess, em meio ao contexto pandêmico. Construímos o que chamamos de "Plano Covid", em que as ações que se particularizaram nesse período se tornaram prioritárias, para realizar a defesa dos serviços prestados à população, das nossas normativas e autonomia profissional, cada vez mais atacadas por processos de controle da nossa força de trabalho e de reconfiguração das políticas sociais em sentido regressivo. Apontamos o debate sobre as relações de trabalho e sobre organização política junto a toda a classe trabalhadora, sem corporativismo, somando na luta antirracista, anticapitalista, feminista e antifascista. Enfrentamos as adversidades, para dar continuidade ao legado do Conjunto Cfess-Cress, ao lado das demais entidades nacionais, como Abepss e Enesso, cunhando na história importantes espaços de resistência, dentre eles fóruns, como o 


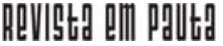

\} O CFESS SE MANIFESTA - CFESS \}

DOI: $10.12957 /$ REP.2021.60310

Fórum Nacional em Defesa da Formação e do Trabalho com Qualidade em Serviço Social, o Fórum Nacional pela Democratização da Comunicação (FNDC), Fórum Nacional de Trabalhadores e Trabalhadoras do Sistema Único de Assistência Social (FNTSuas), Fórum Nacional da Reforma Urbana (FNRU); frentes, como a Frente Nacional contra a Privatização da Saúde e a Frente Nacional contra a Criminalização das Mulheres e pela Legalização do Aborto; e a participação e articulação com outros fóruns e frentes da sociedade civil, em parceria com outras entidades da área da seguridade social e da defesa dos direitos humanos, como conselhos de direitos e de políticas, dentre eles, Conanda - Conselho Nacional dos Direitos da Criança e do Adolescente, CNAS - Conselho Nacional de Assistência Social e CNS - Conselho Nacional de Saúde.

\section{Situando a crise e o contexto pandêmico}

A crise estrutural e a crise conjuntural são processos que estabelecem relações entre si. A crise sanitária revela e escancara as desigualdades sociais, originadas e explicadas na estrutura do modo de produção capitalista, racista e patriarcal. Sociabilidade construída pela dominação de classe e de exploração, que nega o atendimento às reais necessidades humanas. $\mathrm{O}$ trabalho profissional não está fora desta lógica e é afetado e tensionado pelas formas como o capital se reorganiza, o que referenda nossas exigências éticas, considerando o neoconservadorismo e o neoliberalismo presentes. Esse projeto que se ergueu com base na exaltação da desrazão/na anticiência, nas violências e nos preconceitos.

Nessa conjuntura, a efervescência da luta de classes está expressa nos antagonismos e nas contradições de interesses, que polarizam as decisões e os caminhos da política - polarização entre economia e vida; entre transporte de jatinho e transporte público lotado; entre testes particulares e decisões que causam genocídio da população; "fique em casa" e a ausência de casa e proteção para a maioria da população brasileira; incentivos a banqueiros e burocracia no auxilio emergencial para a população; a manipulação de dados para justificar aberturas do comércio e outros serviços. Essas dicotomias expressam um projeto em curso na nossa sociedade, que tensiona a correlação de forças, para que as forças do capital vençam o trabalho.

Nosso fio condutor segue sendo as reflexões éticas, numa concepção não abstrata, conectada com a realidade histórica e os dilemas da vida social. Assim, temos alguns registros deste tempo presente.

\section{Os registros dramáticos dos retrocessos de direitos conquistados}

O Pantanal em chamas, Amapá por dias sem energia elétrica, povos indígenas sofrendo etnocídio, população negra atacada com o superencarceramento e a violência institucional, diversos ataques à autonomia reprodutiva das mulheres e pessoas com capacidade de gestar, a população 
em situação de rua sob constante ameaça de enclausuramento em comunidades terapêuticas. Intensas contrarreformas no campo dos direitos trabalhistas e desfinanciamento das políticas sociais. Aumento da precarização do trabalho e congelamento dos investimentos na área social. Tentativas de recrudescer o desmonte da seguridade social e o ataque aos direitos humanos.

E desafios de curto a longo prazo de responder aos imperativos da defesa da democracia, das condições de trabalho e defesa dos direitos humanos. Defesas estas que não poderemos realizar sozinhos/as, mas com as forças sociais e políticas dispostas a fortalecer processos de democratização da sociedade brasileira, na contramão do movimento hegemônico constituído.

Denunciamos os ataques à população indígena, no Dia Internacional dos Povos Indígenas, debatendo sobre atuação profissional e a pandemia nas aldeias. Também falamos sobre o racismo institucional e religioso, apontando casos de racismo que ganharam repercussão na mídia, reforçando a continuidade de ações antirracistas de assistentes sociais, para além da campanha do Conjunto Cfess-Cress. Denunciamos o ataque aos direitos das pessoas com deficiência, defendendo a revogação do Decreto $\mathrm{n}^{\circ}$ 10.502/ 2020, que institui a Política Nacional de Educação Especial. Denunciamos os ataques fundamentalistas, em defesa da vida das mulheres e das meninas, das vidas negras, e seguimos na luta pela renda básica para toda a população e nas articulações em defesa da Lei 13.935/19 (assistentes sociais e psicólogos/ as na educação), com objetivo de regulamentar a normativa nos municípios. Importante nos mantermos na tradição incansável de denúncia dos efeitos dos projetos de privatização do patrimônio e serviço público estatal, reafirmando nosso compromisso, como assistentes sociais, com a garantia e ampliação do acesso da população aos direitos sociais e humanos.

Também comemoramos os 30 anos do Estatuto da Criança e do Adolescente (ECA), importante conquista que vem duramente sendo atacada para retroagir. Defendemos o Sistema Único de Saúde (SUS), a saúde pública e estatal, e estamos na luta contra a privatização da saúde. Seguimos na defesa do Sistema Único de Assistência Social (Suas) e da organização das trabalhadoras e dos trabalhadores desta área. Realizamos a defesa da previdência social pública e nos contrapusemos aos ataques ao serviço social do INSS e da Reabilitação Profissional.

\section{A história segue em nossas mãos: posicionamentos do Conjunto Cfess-Cress}

Na Plenária Nacional realizada em 2020, com participação de todos os Cress e do Cfess, pudemos reafirmar nossas lutas contra as barbáries do capitalismo contemporâneo, tendo como horizonte a construção de sociedade sem exploração e opressões e a defesa e compromisso do conjunto 


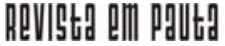

\} O CFESS SE MANIFESTA - CFESS \}

DOI: $10.12957 /$ REP.2021.60310

com a valorização da profissão: seus valores ético-políticos e pela qualidade dos serviços prestados à população.

De lá, as propostas para o triênio, em cada eixo temático para as ações do conjunto, podem ser resumidas nos seguintes pontos centrais:

No administrativo-financeiro, as propostas aprovadas ratificaram a concepção ético-política, com preocupações quanto à materialidade das ações e a sustentabilidade do Conjunto Cfess-Cress. A necessidade de garantir a sustentação financeira, no equilíbrio entre as condições do rebaixamento de salários da categoria e o fortalecimento da profissão regulamentada, reconhecida e respeitada socialmente.

Na seguridade social, a reafirmação de sua concepção de forma ampliada e o comprometimento com as bandeiras de luta. Reafirma-se a luta contra o governo autoritário e contra cortes de recursos e direitos sociais e a unidade do conjunto quanto aos princípios éticos que sustentam essas lutas. Destaca-se a histórica inserção do tema da assistência social, da saúde e da previdência social em suas pautas, a defesa da renda básica universal, a defesa de política para população em situação de rua, a defesa de política de arte e cultura e a continuidade da luta pela implementação da Lei da Educação.

Na orientação e fiscalização profissional, as propostas reafirmaram a Política Nacional de Fiscalização em suas dimensões: afirmativa de princípios; normativa e disciplinadora; político-pedagógica. As principais preocupações referem-se à defesa de condições éticas e técnicas do trabalho profissional e, principalmente, proposições de estratégias para enfrentamento das requisições indevidas, tendo como foco a defesa dos serviços prestados à população e a qualidade do trabalho profissional.

$\mathrm{Na}$ ética e direitos humanos, há um crescimento de propostas com a temática de defesa dos direitos humanos no repertório da categoria profissional, reiterando a sua necessidade pujante e o crescimento desta pauta. Afirma-se o compromisso ético com a análise crítica e construção de mediações para desenvolver uma cultura política com direção emancipatória e respeito à diversidade humana. E também a necessidade de articulação com os movimentos sociais de luta, bem como a valorização da ética, na perspectiva de reconhecer, analisar e se contrapor às formas de banalização da vida social.

$\mathrm{Na}$ formação e relações internacionais, os temas são concisos, mas com muitas interfaces com o Fórum em Defesa da Formação e do Trabalho Profissional e a necessidade de fazer crescerem iniciativas de fóruns regionais e de articulação com o exercício profissional. A defesa das residências multiprofissionais em saúde se faz presente. E, ainda, a necessidade de assegurar a comissão de formação dos Cress, para dar sustentação a ações articuladas com Abepss, Enesso, unidades de ensino, na perspectiva de formação continuada. 
Na comunicaçã,o há o compromisso com sua defesa como direito humano, com o fortalecimento e aperfeiçoamento da Política Nacional de Comunicação, pensada como estratégia de diálogo com a categoria e com a sociedade, apontando a necessidade de se construírem estratégias para o enfrentamento do racismo estrutural em suas formas e manifestações institucionais. Os temas para as campanhas do Dia da/o Assistente Social e do triênio reafirmam o compromisso com a defesa dos povos originários e comunidades tradicionais e a centralidade nas mulheres, para denunciar as formas de opressão e do trabalho explorado.

Além disso, as notas e orientações expedidas, como o CFESS Manifesta no "Dia Internacional de Luta contra a Tortura: vidas negras importam!", denunciando que o Estado brasileiro segue torturando a população preta e periférica; sobre os retrocessos da 'Reforma Administrativa', que prevê uma verdadeira desestruturação do sistema público de garantia de direitos; e para o "Dia Latino-Americano e Caribenho pela Descriminalização e Legalização do Aborto", destacando nossa luta por políticas públicas, justiça reprodutiva e pela legalização do aborto.

Temos recomendado que assistentes sociais sigam as orientações das autoridades sanitárias com respaldo científico sobre as regras de isolamento e quarentena, além de reivindicar o uso dos Equipamentos de Proteção Individual e Coletiva. Temos também respondido a dúvidas e a questões sobre o contexto do trabalho profissional. Por meio das Comissões de Orientação e Fiscalização (Cofis), juntamente com outras comissões e as assessorias jurídicas, temos debatido e apresentado respostas a demandas emergentes. Realizamos uma série de entrevistas do Cfess, que debatem a atuação profissional durante a pandemia da Covid-19, além de material audiovisual que valoriza o trabalho de assistentes sociais e as ações do Conjunto Cfess-Cress.

As normativas e resoluções expedidas pelo Conjunto buscam dar segurança jurídica para a categoria, como a Resolução CFESS nº 940/2020, que suspendeu os prazos dos processos éticos; a Resolução CFESS no 942/ 2020, que estendeu o prazo para pagamento das anuidades, e a Orientação Normativa CFESS no 3/2020, que reforçou que comunicação de óbito não é atribuição ou competência de assistentes sociais.

O Parecer Jurídico de 5 de abril de 2020 dispôs sobre ausência de equipamentos de proteção individual para assistentes sociais e medidas jurídicas cabíveis; a Resolução CFESS no 951/ 2020 autorizou, em caráter excepcional, o envio de documentos por e-mail nos pedidos de inscrição, reinscrição e transferência nos Cress em que o atendimento estiver se realizando remotamente, enquanto perdurarem as restrições impostas pela pandemia do novo coronavírus (Covid-19).

Ainda assim, temos inúmeros desafios na direção de uma entidade que busca fortalecer e sustentar a materialização de nossas defesas. As orientações, recomendações e normativas expedidas pelo Conjunto Cfess-Cress 


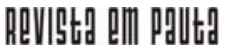

\} O CFESS SE MANIFESTA - CFESS \}

DOI: $10.12957 /$ REP.2021.60310

têm sido fundamentais para o trabalho de assistentes sociais. Mas segue sendo desafiador, na atual conjuntura:

- O enfrentamento de retrocessos e ataques aos direitos da classe trabalhadora;

- A construção de planos de ação que considerem as demandas do cotidiano profissional;

- A visibilidade das ações em defesa da profissão e do projeto ético-político;

- O fortalecimento político-administrativo do Conjunto CfessCress;

- O planejamento orçamentário, numa perspectiva não mecanicista, que aponte resultados e ações exequíveis e incorporado como ferramenta de gestão;

- Planejamento de ações que incorpore as Bandeiras de Luta e as Ações Estratégicas Continuadas;

- Fortalecimento dos instrumentos político-normativos: a Lei 8662/93, Código de Ética Profissional, resoluções, na perspectiva da autonomia profissional;

- Articulação e execução de ações em defesa do trabalho profissional, dos direitos humanos e da seguridade social ampliada.

Sabemos serem inúmeras as tarefas, e muito complexas em tempos de pandemia, mas estamos atentas e atentos aos rebatimentos para a profissão e para toda a classe trabalhadora no pós-pandemia. Necessitamos, nesse contexto histórico, seguir organizando nossa esperança e construindo a história, como nos recomenda o poeta em sua sabedoria. Fecharemos o ano de 2020 renovando a esperança em dias melhores, construindo uma agenda política à altura de nossa história e com disposição para a luta coletiva, arregimentando as forças progressistas para o enfrentamento do autoritarismo e de todas as formas de violência. O projeto ético-político segue sendo nosso horizonte.

Conselho Federal de Serviço Social (Cfess)

Gestão Melhor ir à luta com raça e classe em defesa do Serviço Social (2020-2023)

DOI: $10.12957 /$ rep.2021.60310

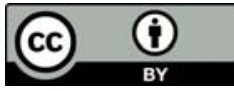

A Revista Em Pauta: Teoria Social e Realidade Contemporânea está licenciada com uma Licença Creative Commons Atribuição 4.0 Internacional. 